\title{
Experimental Study on Fire Resistance of Reinforced Concrete Frame Structure
}

\author{
Xuan ZHANG ${ }^{1, a}$, Qing-Qing SHEN ${ }^{1, b}$, Zhong-Yi LI ${ }^{1, \mathrm{c}}$, Song-Hua TANG ${ }^{2, \mathrm{~d}}$, \\ Ying-She LUO ${ }^{1, e^{*}}$
}

${ }^{1}$ Hunan Province Key Laboratory of Engineering Rheology, Central South University of Forestry and Technology, Changsha 410004, Hunan, China

\author{
${ }^{2}$ School of Civil Engineering, Central South University, Changsha 410075, Hunan, China \\ a420326691@qq.com, b1039095517@qq.com, '263797728@qq.com, dtangsh2003@aliyun.com, \\ $\mathrm{e}^{\star}$ Iys0258@vip.sina.com
}

${ }^{*}$ Corresponding author

Keywords: High Temperature, Frame Structure, Fire Load, Fire Temperature, Structure Strength.

\begin{abstract}
The fire tests included fire load and fire temperature had been conducted to nine reinforced concrete frame structures with ISO834 standard heating up curve. Furthermore, the static load tests had also been done under room temperature to the above nine structures after cooling and one reinforced concrete frame structure which with the same shape and sizes but had not undergone the fire test. The experiments showed that the fire temperature effect on the specimen was larger than the fire load. The larger fire load and a higher temperature of the specimen had the larger influence on the mechanical properties such as bearing capacity and deformation. The limit load of the frame structure decreased $36.9 \%$ under $600{ }^{\circ} \mathrm{C}$; when under $800^{\circ} \mathrm{C}$, decreased $48 \%$; under $1000^{\circ} \mathrm{C}$, the frame structure basically lost its bearing capacity, it decreased $57.3 \%$.
\end{abstract}

\section{Introduction}

Fire causes heavy loss of life and property safety to humans every year, which is one of the most frequent and devastating disasters in the nature. Statistics showed that building fire[1] had had the most times and serious loss. Therefore, study the fire resistance of reinforced concrete structures, on the one hand is to establish a set of reasonable and convenient for fire resistance design method, on the other hand is to make scientific and accurate evaluation for the damage degree of building structure, to reduce fire loss, shorten the function recovery time of the structure and provide a basis for fire resistance design of building structure.

The study of reinforced concrete structure under high temperature abroad were earlier than the domestic scholars[2-4]. According to research of the stress distribution, the action of deformation and failure characteristics of structure under the effect of load and high temperature, they presented design theory and analyses method about the fire resistance of reinforced concrete structure analysis. Domestic Ya-xiongYao[5], considering the single, double span bearing temperature and other factors, studied the fire resistance test of two span continuous beams. Xu-dong Shi, zhen-hai Guo[6]took five pin framework for fire test on three sides. They got the appeared rule of plastic hinge, the destructive mechanism and ultimate bearing capacity of the framework under the high temperature. In general, experimental study of the under and after fire on reinforced concrete frame structure was less, let alone the contrast experiments to the structures without fire load and undergone fire load, under the static load and normal temperature[7-9].

The fire tests with fire load and fire temperature for nine reinforced concrete frame structures with ISO834 standard heating up curve had been conducted. Then, for comparison, the static load tests to the structures with the same shapes and sizes, but which subjected to the fire and without subjecting any fire had also been finished. The influence between fire resistance of the fire load and temperature had been studied. There are some important conclusions which can be partly applied to fire resistance design of concrete structure. 


\section{The Summary of Test}

\section{The Parameters of Test}

Ordinary Port-land cement numbered 42.5 was used for making the reinforced concrete specimens, the proportion of concrete was: cement: water: sand: stone was equal to 1: 0.617: 2.257: 4.127. Artificial stirring was used for all concrete specimens, then mechanical vibrating to them and packing them into moulds with flat. The form and sizes, reinforcement and load of specimen, were shown in fig. 1 .

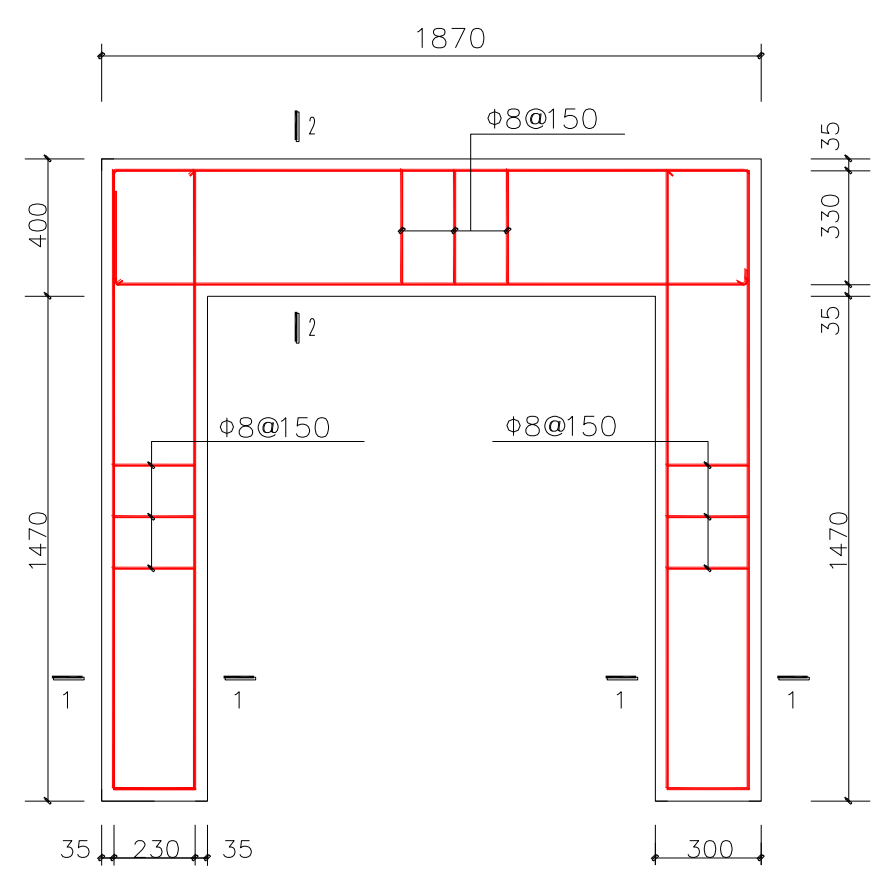

(a)

(a) Shape and sizes of specimen

(c) Reinforcement of 2-2 cross-section

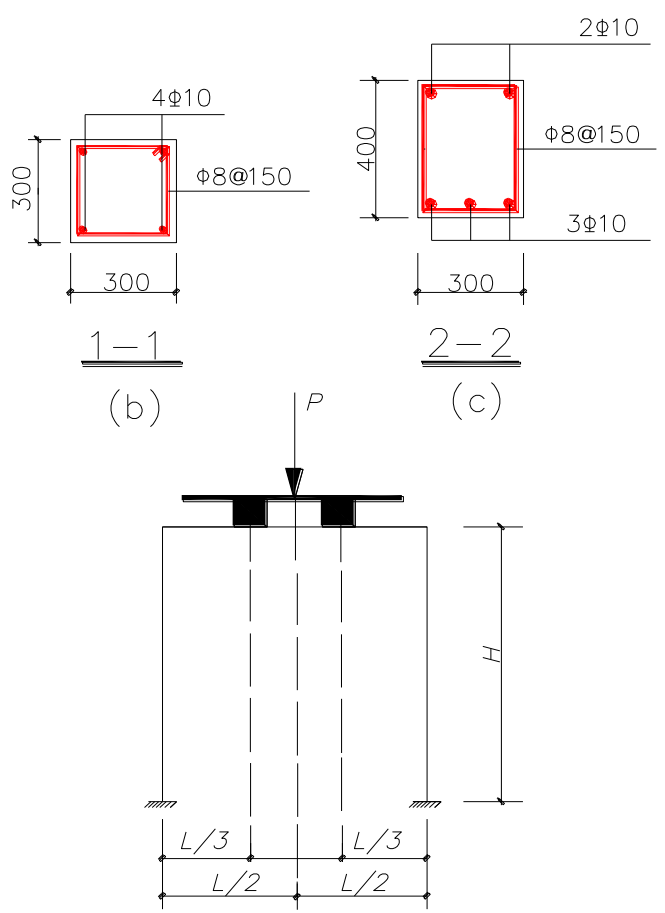

(d)

(b) Reinforcement of 1-1 cross-section;

(d) Loading way

Fig. 1 Shape and Sizes of Specimen, Reinforcement and Load Schematic Diagram

\section{The Conditions and Steps of Test}

The specimens had been tested by fire treatment furnace in Railway Institute of Central South University, 11 specimens of reinforced concrete frame were made in the tests. in addition to a framework for normal temperature test and one standby, the remaining nine specimens were used in high temperature tests. Five sides named front, behind, left, right and bottom surface of specimen were subjected to fire, only the upper surface contacted with the normal temperature. Using ISO834 standard heating up curve, as soon as reaching the expected temperature, it should be kept at the temperature level to 120 minutes. Three different temperature levels and load levels were applied to the nine specimens respectively. The specimens condition parameters were shown in table 1 .

Table 1 Test Condition Parameters

\begin{tabular}{c|ccccccccc}
\hline Specimen number & $\mathrm{T} 1$ & $\mathrm{~T} 2$ & $\mathrm{~T} 3$ & $\mathrm{~T} 4$ & $\mathrm{~T} 5$ & $\mathrm{~T} 6$ & $\mathrm{~T} 7$ & $\mathrm{~T} 8$ & T9 \\
\hline Test temperature $\left({ }^{\circ} \mathrm{C}\right)$ & 600 & 800 & 1000 & 600 & 800 & 1000 & 600 & 800 & 1000 \\
\hline Static load value $(\mathrm{kN})$ & 21 & 21 & 21 & 28 & 28 & 28 & 35 & 35 & 35 \\
\hline
\end{tabular}

After the fire test, remove the specimen from the furnace into air, then it cooled to normal 
temperature level naturally, then the static load tests to the above nine specimens were done by using the instrument named $500 \mathrm{kN}$ hydraulic jack until them ruptured, so was also dealed with the specimen never fired. At the same time, the changes the midspan deflection of specimen with time increased were measured. The loading mode and loading method for the static load tests to all of the ten specimens were the same with them under the high temperature levels as shown in Fig.2.

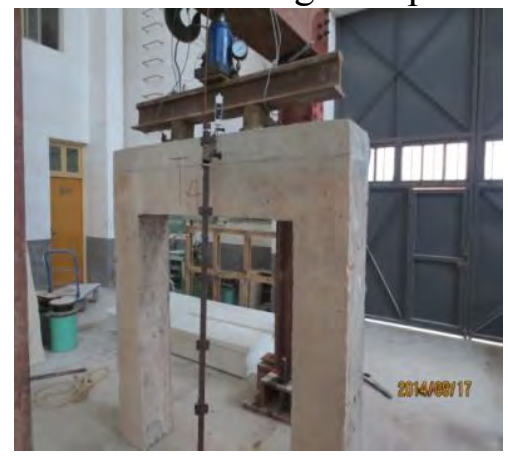

Fig. 2 The Loading Method of Test

\section{The Test Phenomena and Failure Process}

\section{Frame Specimens Apparent Phenomena after the Fire}

With the heating temperature from the room temperature to $1000^{\circ} \mathrm{C}$, the physical state of reinforced concrete frame specimens changed gradually. The surface characteristics of them under the different temperature levels were shown in Fig.3.

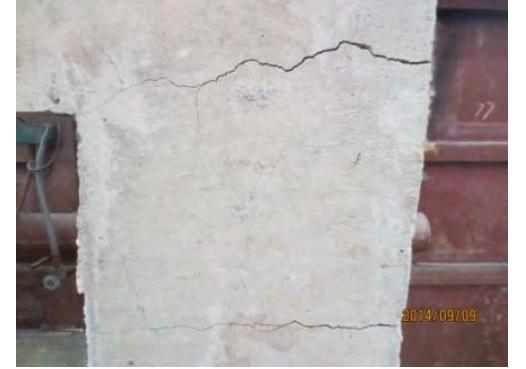

(a) Local surface characteristics $\left(600^{\circ} \mathrm{C}\right)$

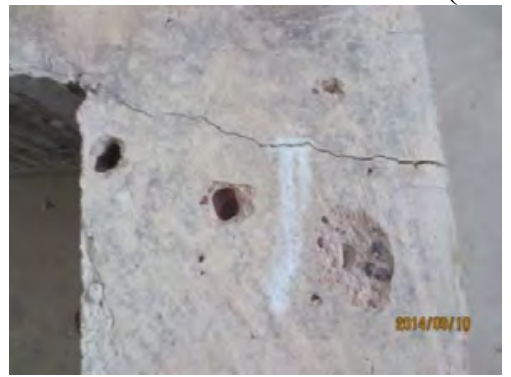

(c) Local surface characteristics $\left(1000^{\circ} \mathrm{C}\right)$

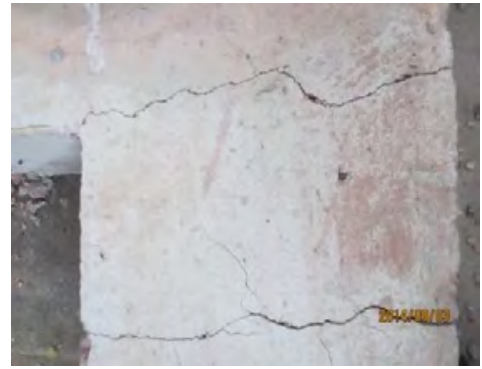

(b) Local surface characteristics $\left(800^{\circ} \mathrm{C}\right)$

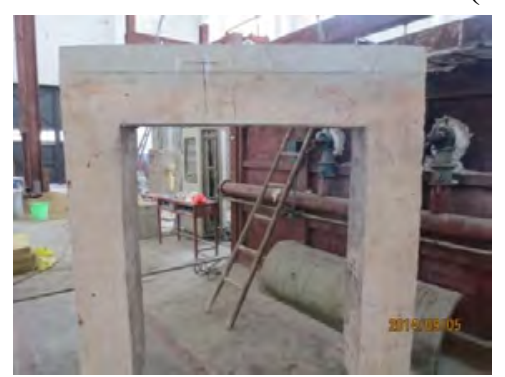

(d) Total Surface characteristics $\left(600^{\circ} \mathrm{C}\right)$

Fig.3 The Surface Characteristics of Specimens under Different Temperature Levels

In the heating process of specimen, when the temperature level reached to $300^{\circ} \mathrm{C}$, the water vapor from the top of specimen escaped. It escaped to the largest amount at about $500{ }^{\circ} \mathrm{C}$, then it reduced gradually, after about $600^{\circ} \mathrm{C}$ water vapor was almost invisible. After high temperature test, one could see the shallow red color on the fired surfaces of specimens, the higher the temperature the deeper red, but the topper color of specimens kept the original one. The Heated surfaces had got a large number of tiny need-like cracks, looseness and some concrete had even burst. Due to the persistent load effect, larger cracks occurred near the beam-column joints.

\section{The Ruptured Characteristics of Framework Specimen under Static Load Test}

Specimen T10(see Fig.4a) was the room temperature specimen, with the increase of load, near 
the top of the frame beam and the bottom of midspan cracks had occurred in succession, then increased in number and width gradually. More cracks which appeared at the top of the frame beam than at the bottom of the frame midspan, lots of cracks appeared between the two loading points along beam bottom. When specimen near to be destroyed, cracks appeared at the outside of the frame column top and the inside of pillars' bottom. Finally shear failure occurred accompanied with the yield formation at the beam-span and the ends of the reinforcing steel.

T1-T9 (see Fig.4b) were the specimens under static load test which had undergone the high temperature tests. With the increase of load, tensile cracks become wider, gradually to the compressive zone, the deflection was also increased. When the load increases to a certain value, and multiple tensile cracks formed into a main crack, finally bending destroy occurred. The main crack width of specimen was bigger; deflection was bigger obviously. With respect to specimens T3 and T8 not only bending failure occurred, but also shearing failure happened near the beam ends.

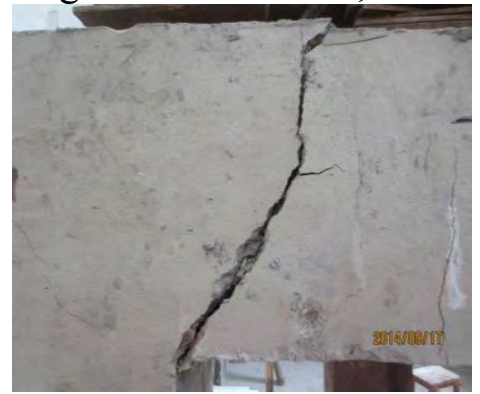

(a) Shearing failure

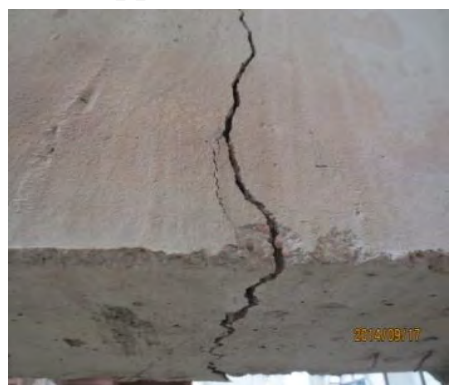

(b) Bending failure

Fig.4 Two destroyed types of static load test

\section{Analysis of Test Results}

Tab.2 Ultimate Load and the Correspond Deflection to Every Specimen

\begin{tabular}{c|c|c|c|c|c|c|c|c|c|c}
\hline $\begin{array}{c}\text { Specimen } \\
\text { number }\end{array}$ & $\mathrm{T} 1$ & $\mathrm{~T} 2$ & $\mathrm{~T} 3$ & $\mathrm{~T} 4$ & $\mathrm{~T} 5$ & $\mathrm{~T} 6$ & $\mathrm{~T} 7$ & $\mathrm{~T} 8$ & $\mathrm{~T} 9$ & $\mathrm{~T} 10$ \\
\hline $\begin{array}{c}\text { Ultimate } \\
\text { load(kN) }\end{array}$ & 236.4 & 184.7 & 162.1 & 224.2 & 171.5 & 148.3 & 201.4 & 188.9 & 138.1 & 349.5 \\
\hline $\begin{array}{c}\text { Fire test } \\
\text { deflection } \\
(\mathrm{mm})\end{array}$ & 2.3 & 2.5 & 2.6 & 3.2 & 3.8 & 4.2 & 3.3 & 3.7 & 4.5 & 0 \\
\hline $\begin{array}{c}\text { Static load } \\
\text { deflection } \\
(\mathrm{mm})\end{array}$ & 9.4 & 10.5 & 12.4 & 10.3 & 11.3 & 13.4 & 10.7 & 12.4 & 13.8 & 6.1 \\
\hline \hline
\end{tabular}

Hierarchical loads were applied to static load tests, the deflection values under every load level were measured and recorded until the destruction of each specimen. To every ultimate load P of the specimens there correspond deflection value under the static load test and fire test. All of them were shown in Table 2.

\section{The Effects of Temperature on the Ultimate Load and Deformation of Frame Specimen}

From Table 2 and Fig.5, one could see the increasement of the midspan deflection of the specimen during the heating process and static load test. In order to compare the temperature effect on the ultimate load and deflection of the specimen, one could analyze specimens of T1, T2 and T3 under the same fire load as an example. Whatever during the process of fire load and under the static load test, the deflection increasement of the specimen was bigger under higher temperature than lower temperature That was to say, the higher temperature of test, the bigger of the deformation of the specimen, the lower of the stiffness of the specimen, so that it would be more 
difficult to withstand the load.

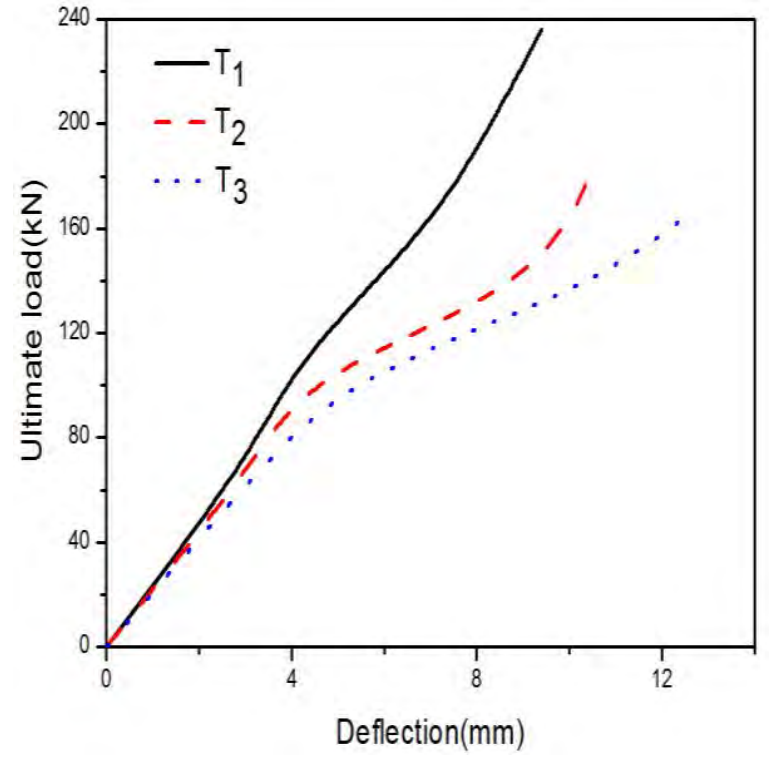

(a) After the fire load test of $21 \mathrm{kN}$

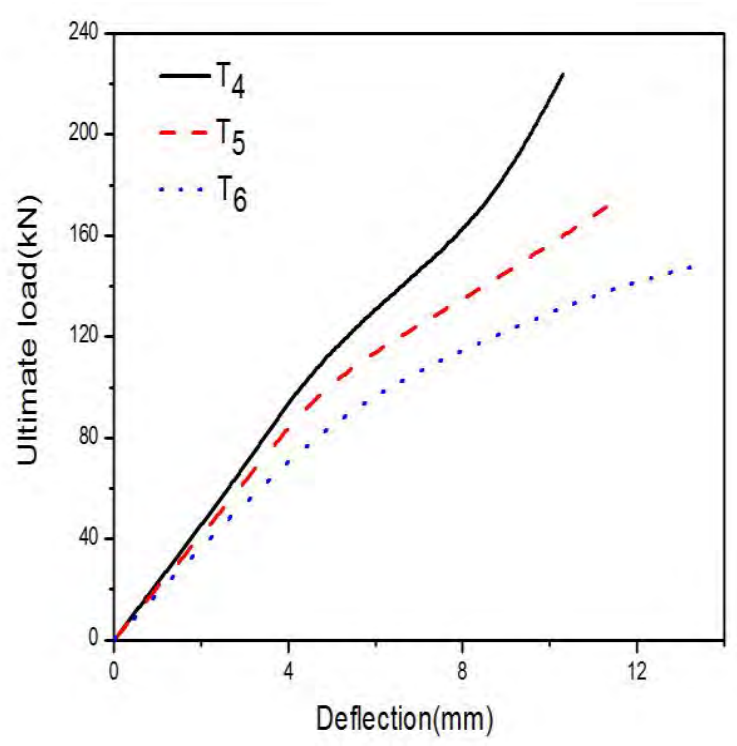

(b) After the fire load test of $28 \mathrm{kN}$

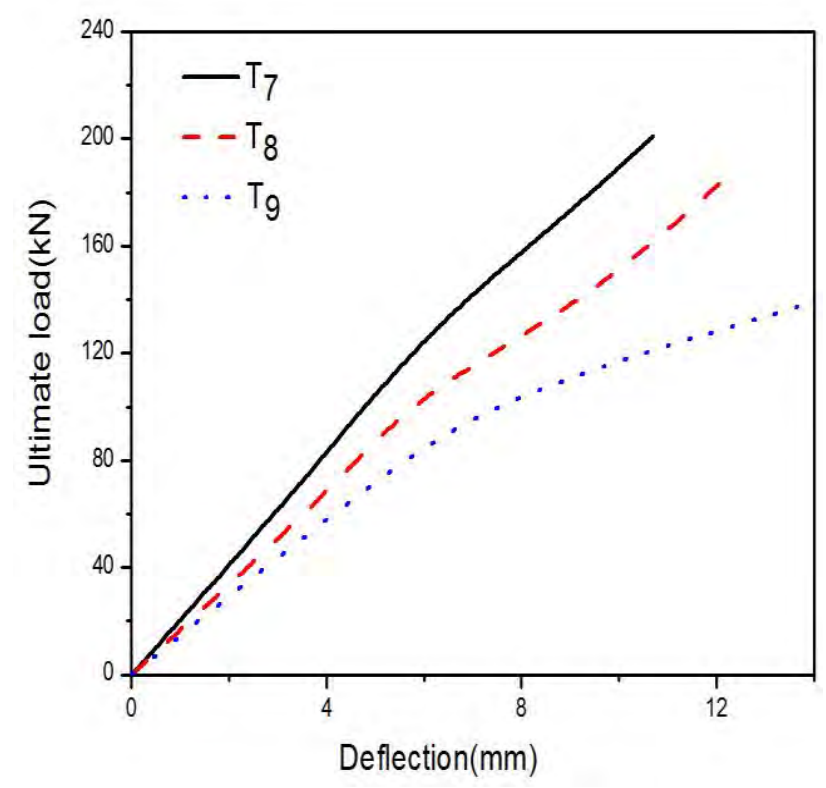

(c) After the fire load test of $35 \mathrm{kN}$

Fig.5 The Relationship Curves of Different Ultimate Load vs Deflection

\section{The Effects of Fire Load on the Ultimate Load and Deformation of Frame Specimen}

In order to compare the influence of the fire load on the ultimate load and the deflection of the frame specimens, the test results of the three groups of specimens were shown in Fig.6, such as the specimens $\mathrm{T} 1, \mathrm{~T} 4$ and $\mathrm{T} 7$; or $\mathrm{T} 2, \mathrm{~T} 5$ and $\mathrm{T} 8$ and or $\mathrm{T} 3, \mathrm{~T} 6$ and $\mathrm{T} 9$ undergone the same fire temperatures $600^{\circ} \mathrm{C}, 800^{\circ} \mathrm{C}$ and $1000^{\circ} \mathrm{C}$ respectively. As the fire load range of the specimens had only reached to $5 \%-10 \%$ of ultimate load under normal temperature, we could draw out a conclusion that when the fire at a certain temperature, the degree of the curve change was relatively closed. When the fire load was small, it had little effect on the deflection and ultimate load of the specimen, but the opposite was greater. Overall, when the specimen with a certain load in the fire, the deflection of the specimen would be bigger after the fire, the specimen's ability to withstand the load could also be reduced. But the specimen T8 was a strange example. Although it was subjected a bigger fire load, it could also bear a bigger ultimate load than T2 and T5 under the room temperature. 


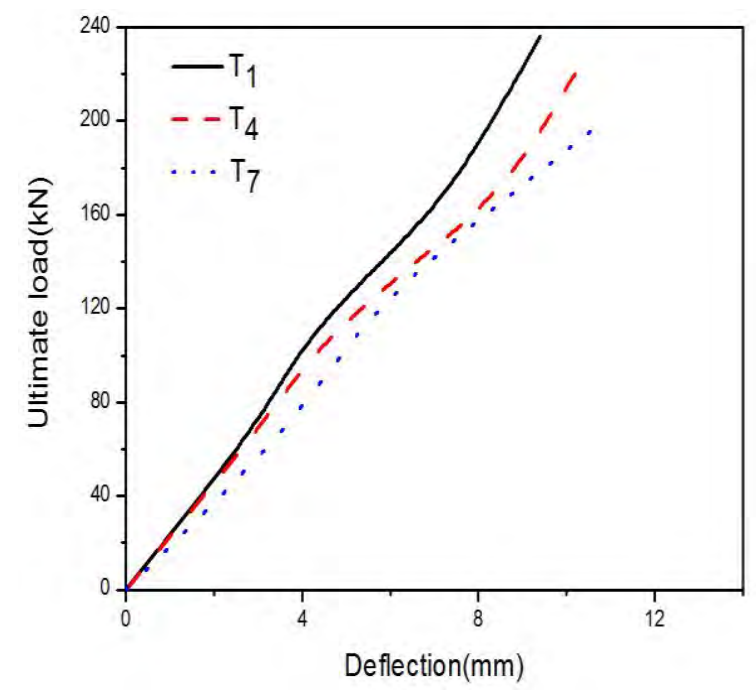

(a) After the fire temperature $600^{\circ} \mathrm{C}$

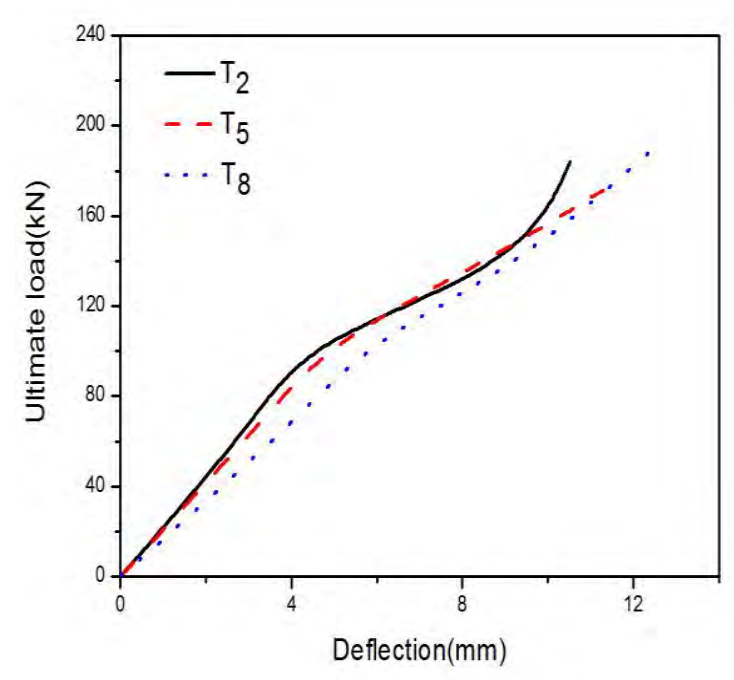

(b) After the fire temperature $800^{\circ} \mathrm{C}$

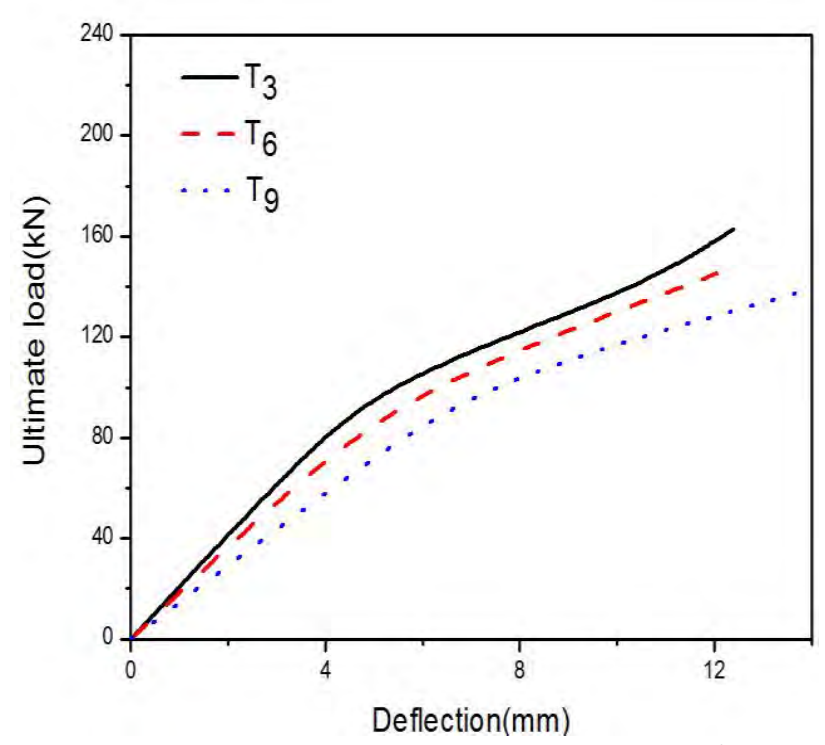

(c) After the fire temperature $1000^{\circ} \mathrm{C}$

Fig.6 The Relationship Curves of Different Ultimate Load vs Deflection

\section{Summary}

(1) The change of the performance of reinforced concrete frame structure after fire test showed that fire temperature and fire load had a certain influence on the performance of specimen. The influence of the fire temperature was larger than the fire load. Interaction between load and high temperature made the deformation of the specimen increase after fire, while the strength and stiffness reduce.

(2) The strength of the reinforced concrete frame structure under the high temperature decreased obviously. The ultimate load of the frame structure decreased $36.9 \%$ under $600{ }^{\circ} \mathrm{C}$; under $800^{\circ} \mathrm{C}$, decreased $48 \%$; under $1000^{\circ} \mathrm{C}$, the frame structure almost lost its bearing capacity, it decreased $57.3 \%$.

\section{Acknowledgements}

This work was financially supported by National Natural Science Foundation(51178474) . The authors want to express their gratitude to Yan ZHANG of Railway Institute of Central South University. 


\section{References}

[1]L.S. Dong. Xiangshan Science Conference. Vol. 2 (1997):35-39 (In Chinese).

[2]J.M. Becker and B. Bresler. Reinforced Concrete Frames in Fire Environments. ASCE, Jan, 1977: $211-224$.

[3]T.T. Lie, R.J. Irwin. Journal of Structural Engineering. Vol. 121(1995): 797-805.

[4]V.K.R. Kodur. Journal of Constructional Steel Research. Vol. 51(1999): 21-26.

[5]Y.X. Yao. A thesis of Tongji University, Shanghai, 1991:60-68 (In Chinese).

[6]X.D. Shi, Z.H. Guo. China Civil Engineering Journal. Vol. 6(2000):6-16 (In Chinese).

[7]S.H. Tang, A thesis of Xiangtan University, Xiangtan, 2010:30-33(In Chinese)

[8]S.H. Tang, Y.S. Luo, S.P. Yin, Y.H. Li, C. Chen, F. Tian. Advanced Materials Research. Vols. 639-640 (2013):1193-1199.

[9]C. Chen, Y.S. Luo, S.H. Tang, X. Zhang. Applied Mechanics and Materials. Vols. 351-352 (2013):460-466. 